\title{
Knowledge, attitude and practices of COVID-19 among medical laboratory professionals in Zambia
}

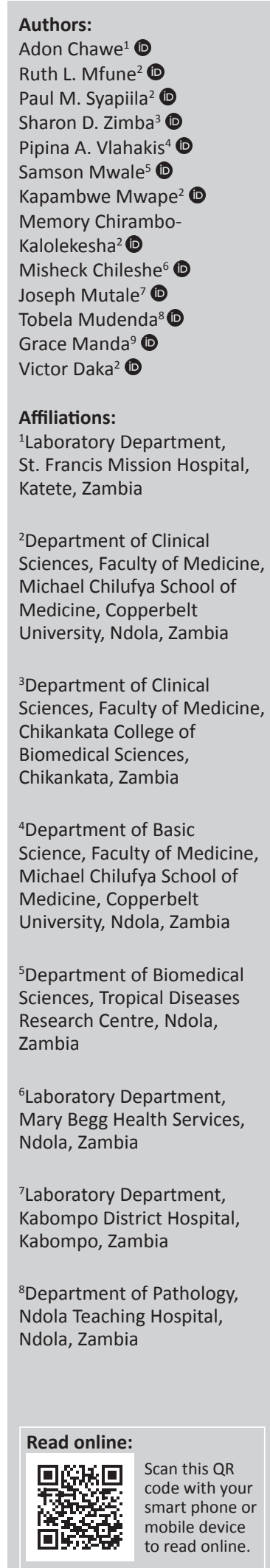

Background: Coronavirus disease 2019 (COVID-19) is a novel disease that has spread to nearly every country worldwide. Medical laboratory professionals are key in the fight against COVID-19 as they provide confirmatory diagnosis for subsequent management and mitigation of the disease.

Objective: This study investigated the knowledge, attitude and practices of COVID-19 and their predictors among medical laboratory personnel in Zambia.

Methods: We conducted a cross-sectional study among medical laboratory professionals in Zambia from 10 to 29 June 2020. Data were collected using Google Forms and exported to Statistical Package for Social Sciences version 23 for statistical analysis. Independent predictors of COVID-19 knowledge and practices were determined. Adjusted odds ratios (AOR) and their $95 \%$ confidence intervals (CI) are reported.

Results: A total of 208 medical laboratory professionals, 58.2\% male, participated in the study. The majority of respondents had good knowledge $(84.1 \%)$ and practice $(75.0 \%)$ regarding COVID-19. Predictors of good knowledge included having a bachelor's degree (AOR: 5.0, CI: 1.13-22.19) and having prior COVID-19 related training (AOR: 8.83, CI: 2.0338.44). Predictors of good practice included having a master's or Doctor of Philosophy (PhD) qualification (AOR: 5.23, CI: 1.15-23.87) and having prior COVID-19 related training (AOR: 14.01, CI: 6.47-30.36).

Conclusion: Our findings revealed that medical laboratory professionals in Zambia have good knowledge regarding COVID-19. There is need for continuous professional development to ensure that medical laboratory professionals are well informed and aware of best practices to aid in curbing the pandemic.

Keywords: COVID-19; medical laboratory professional; knowledge; attitude; practices.

\section{Introduction}

Coronavirus disease 2019 (COVID-19) is a respiratory disease caused by severe acute respiratory syndrome coronavirus $2 .{ }^{1}$ Coronaviruses have been known to affect humans, infecting the respiratory tract and causing infections ranging from mild to severe. ${ }^{2}$ In the past, different strains of coronaviruses have caused severe acute respiratory syndrome and Middle East respiratory syndrome. Research has shown that COVID-19 is more contagious compared to the previous outbreaks, but less lethal. ${ }^{3}$ Transmission occurs through the inhalation of droplets or contact with surfaces that have been contaminated with the severe acute respiratory syndrome coronavirus 2 . As of this writing, there is currently no known vaccine or documented specific treatment for COVID-19 disease. ${ }^{4}$ Drugs that show potential to treat critically ill patients are still being investigated for safety and efficacy., ${ }^{4,6}$ Prevention and control of the spread of COVID-19 is done by social distancing, wearing face masks to prevent both the inhalation and transmission of infectious droplets, as well as effective hand hygiene by regularly washing hands or using alcohol-based hand sanitisers. ${ }^{7,8}$

The first cases of COVID-19 were reported in December 2019 in Wuhan, Hubei province, central China. Since then, the disease has spread to nearly every country worldwide leading

${ }^{9}$ Laboratory Department, Kalomo District Hospital, Kalomo, Zambia Corresponding author: Ruth Mfune, lindizyani@gmail.com

Dates: Received: 21 Sept. 2020|Accepted: 06 Jan. 2021|Published: 04 Mar. 2021

How to cite this article: Chawe A, Mfune RL, Syapiila PM, et al. Knowledge, attitude and practices of COVID-19 among medical laboratory professionals in Zambia. Afr J Lab Med. 2021;10(1), a1403. https://doi.org/10.4102/ajlm.v10i1.1403

Copyright: ( 2021. The Authors. Licensee: AOSIS. This work is licensed under the Creative Commons Attribution License. 
to the World Health Organization declaring COVID-19 a pandemic on 11 March 2020. ${ }^{9}$ As of 27 October 2020 there were 44055642 confirmed cases and 1168306 deaths reported globally, with 1740720 confirmed cases and 38830 deaths reported in Africa. ${ }^{10}$ In Zambia, 16243 confirmed cases and 348 deaths were reported as of 27 October 2020, including a high proportion of community deaths. ${ }^{11,12}$

Few publications and national situation reports exist that detail the number of healthcare workers (HCWs) including medical laboratory personnel around the world infected with COVID-19. ${ }^{13}$ In China where the disease first started, 2055 HCWs were infected as of 24 March 2020. ${ }^{14}$ In the United States, $9282 \mathrm{HCWs}$ were infected as of 14 April $2020 .{ }^{15}$ The World Health Organization estimates that over 1000 HCWs in Africa had been infected with COVID-19 by 23 July 2020. ${ }^{16}$ Information on the source of infection among HCWs in countries that have recorded the disease remains limited.

Medical laboratory professionals are key personnel in the diagnosis of COVID-19 in Zambia. Although they are not in the front line, which precludes them from prominence, their role in providing confirmatory diagnosis is the main basis upon which cases are identified and clinical management is instituted. The work areas of biomedical laboratory professionals are very hazardous due to both suspected and unsuspected infectious agents. Lack of knowledge and good attitude, as well as poor laboratory practices, can have a twofold effect. Firstly, a wrong diagnosis leading to wrong patient management could portend severe consequences for the patient as well as undermine transmission prevention efforts; this is particularly true with COVID-19. Secondly, poor attitude and practices could result in safety incidents (such as infection transmission) which could be deleterious to both the concerned staff and their immediate environment, including co-workers, families and patients or laboratory clients. ${ }^{17}$

Therefore, this study aimed at evaluating the knowledge, attitudes and practices of medical laboratory professionals in Zambia who are integral in the diagnosis of COVID-19.

\section{Methods}

\section{Ethical considerations}

Ethical clearance for this study was obtained from the Tropical Diseases Research Centre Institution Review Board (registration number: 00002911). The questionnaire contained an information sheet regarding the study and an informed consent statement for participants to agree to participate or not. All participants who declined to take part in the study were immediately withdrawn and could not proceed to respond to the questionnaire. Access to the online portal for the questionnaire was limited to investigators who were assigned user rights by the principal investigator to ensure confidentiality of collected data.

\section{Sample size determination}

We used the methods for calculating the sample size for prevalence studies as described by Pourhoseingholi and others. ${ }^{18}$ Assuming an $82 \%$ prevalence of good knowledge and practice regarding COVID-19 obtained from a similar study among $\mathrm{HCWs}^{19}{ }^{19}$ confidence level of $95 \%$ and a precision level of $5 \%$, we obtained a minimum required sample size of 227 participants. By extrapolating to a finite population of 1900 medical laboratory personnel officially recognised under the medical laboratory register of the Biomedical Society of Zambia, we obtained a final sample size of 204 participants.

\section{Study design}

This cross-sectional survey was conducted among 208 medical laboratory professionals in Zambia. Due to COVID-19 related restrictions imposed during this period, it was not feasible to conduct face-to-face interviews and therefore we administered an online questionnaire using Google Forms (Alphabet, Inc., Mountain View, California, United States).

\section{Data collection}

Content validation of the questionnaire was done by administering the questionnaire to faculty in the Biomedical Sciences unit at the Copperbelt University, Ndola, Zambia. The results from the pre-test were not included in the final analysis but were used to modify the questionnaire based on feedback. The questionnaire had two main components: demographics and knowledge, attitudes and practices. The demographic section had 8 questions while the knowledge, attitudes and practices section was divided into the following subsections: knowledge (8 questions), attitude (5 questions) and practices (13 questions).

To ensure that only target respondents participated in the survey we distributed the link to the survey through the email database and WhatsApp (Facebook Inc, Menlo Park, California, United States) group facilitated by the Biomedical Society of Zambia during data collection from 10 to 29 June 2020. A total of 750 participants were availed the link for the questionnaire. There were 210 medical laboratory personnel who participated in the study, giving a response rate of $28 \%$. Participants who consented to participate in the study by checking the consent box in the preliminary page of the questionnaire were allowed to proceed with the rest of the questionnaire. Only participants who completed the questionnaire by clicking on the 'Submit' button had their responses recorded.

\section{Data management and statistical analysis}

Collected data were downloaded and cleaned in Microsoft Excel (Microsoft Corp., Redmond, Washington, United States) and exported to Statistical Package for Social Sciences version 23 (IBM Corp., Armonk, New York, United States) for statistical analysis. To ensure the 
internal consistency and reliability of the data, we used Cronbach's alpha coefficient according to methods described in a previous study. ${ }^{20}$ We obtained an alpha value of 0.645 , indicating adequate reliability. ${ }^{21}$ The outcome variables in this study were COVID-19 knowledge levels and practice towards COVID-19. Attitude was investigated but limited to descriptive analysis due to the limited number of questions.

TABLE 1: Demographic characteristics of medical laboratory professionals, Zambia, June 2020.

\begin{tabular}{|c|c|c|}
\hline Factor & $\begin{array}{c}\text { Number of } \\
\text { participants }(n)\end{array}$ & $\%$ \\
\hline \multicolumn{3}{|l|}{ Sex } \\
\hline Female & 87 & 41.8 \\
\hline Male & 121 & 58.2 \\
\hline \multicolumn{3}{|l|}{ Age (years) } \\
\hline $20-29$ & 104 & 50.0 \\
\hline $30-39$ & 79 & 38.0 \\
\hline$\geq 40$ & 25 & 12.0 \\
\hline \multicolumn{3}{|l|}{ Current qualification } \\
\hline Certificate in Biomedical Sciences & 2 & 1.0 \\
\hline Diploma in Biomedical Sciences & 155 & 74.5 \\
\hline BSc Biomedical Sciences & 40 & 19.2 \\
\hline MSc Biomedical Sciences & 9 & 4.3 \\
\hline $\mathrm{PhD}$ & 2 & 1.0 \\
\hline \multicolumn{3}{|l|}{ Work experience } \\
\hline Less than 5 years & 106 & 51.0 \\
\hline $5-10$ years & 60 & 28.8 \\
\hline More than 10 years & 42 & 20.2 \\
\hline \multicolumn{3}{|l|}{ Facility type } \\
\hline Clinic laboratory & 14 & 6.7 \\
\hline Health centre laboratory & 26 & 12.5 \\
\hline Hospital laboratory & 134 & 64.4 \\
\hline $\begin{array}{l}\text { Private or non-governmental } \\
\text { organisation }\end{array}$ & 20 & 9.6 \\
\hline Others & 14 & 6.7 \\
\hline \multicolumn{3}{|l|}{ Participant's province } \\
\hline Central & 12 & 5.8 \\
\hline Copperbelt & 61 & 29.3 \\
\hline Eastern & 17 & 8.2 \\
\hline Lusaka & 40 & 19.2 \\
\hline North-western & 18 & 8.7 \\
\hline Northern & 11 & 5.3 \\
\hline Southern & 30 & 14.4 \\
\hline Others & 19 & 9.1 \\
\hline Total & 208 & 100.0 \\
\hline
\end{tabular}

BSc, Bachelor of Science; MSc, Master of Science; PhD, Doctor of Philosophy.
Eight questions were used to assess COVID-19 knowledge, each scoring 1 point for a correct answer. Thirteen questions were asked to determine whether a participant had good practice towards COVID-19 or not, each scoring 1 point for positive practice and 0 for negative practice. Bloom's cut-off of $80 \%^{22}$ was used to determine good knowledge and good practice. Questions were adapted from a previous study. ${ }^{23}$

To identify factors that predict good knowledge and practice towards COVID-19, bivariate analysis was performed. All factors that were statistically significant as reported by $95 \%$ confidence interval (CI) in bivariate logistic regression were included in a forward stepwise multivariate logistic regression model to identify factors that were independently associated with good knowledge and practice.

\section{Results \\ Demographic characteristics}

A total of 208 medical laboratory professionals from seven provinces of Zambia took part in this study. There were more men $(n=121,58.2 \%)$ than women. Half of the participants were aged 20-29 years while more than half had a diploma. Most of the respondents were from a hospital laboratory $(n=134,64.4 \%)$ (Table 1$)$.

Participants showed good knowledge regarding awareness of practical measures to stop the spread of COVID-19 ( $n=208,100.0 \%)$, the techniques used to test for COVID-19 $(n=208,100.0 \%)$ and symptomatic management of COVID-19 ( $n=202,97.1 \%)$ (Table 2 and Table 3). One-quarter $(n=52$, $25.0 \%$ ) of the participants reported being involved in sampling for COVID-19 while slightly over a third ( $n=73$, $35.1 \%$ ) reported having been trained in sample handing and transportation.

\section{Factors associated with COVID-19 knowledge}

A high proportion of respondents were knowledgeable about COVID-19 ( $n=175,84.1 \%)$. Bivariate logistic

TABLE 2: Characteristics of responses for knowledge and practice towards COVID-19, Zambia, June 2020. ${ }^{\dagger}$

\begin{tabular}{|c|c|c|c|c|c|}
\hline \multirow[t]{2}{*}{ KAP aspect } & \multirow[t]{2}{*}{ Question } & \multicolumn{2}{|c|}{ Correct } & \multicolumn{2}{|c|}{ Incorrect } \\
\hline & & $n$ & $\%$ & $n$ & $\%$ \\
\hline \multirow[t]{8}{*}{ Knowledge of COVID-19 } & $\begin{array}{l}\text { The main clinical symptoms of COVID-19 are fever, fatigue, dry cough } \\
\text { and myalgia }\end{array}$ & 194 & 93.3 & 14 & 6.7 \\
\hline & COVID-19 is a disease caused by SARS-CoV- 2 & 177 & 85.1 & 31 & 14.9 \\
\hline & The COVID-19 virus spreads via respiratory droplets of infected individuals & 207 & 99.5 & 1 & 0.5 \\
\hline & Our institution has informed us about COVID-19 & 199 & 95.7 & 9 & 4.3 \\
\hline & I am aware of the practical measures to help stop the spread of COVID-19 & 208 & 100.0 & 0 & 0.0 \\
\hline & I am aware of the techniques used to test for COVID-19 & 208 & 100.0 & 0 & 0.0 \\
\hline & $\begin{array}{l}\text { There currently is no effective cure for COVID-19, but early symptomatic and } \\
\text { supportive treatment can be helpful }\end{array}$ & 202 & 97.1 & 6 & 2.9 \\
\hline & $\begin{array}{l}\text { Persons with COVID-19 cannot transmit the virus to others when a fever is } \\
\text { not present }\end{array}$ & 175 & 84.1 & 33 & 15.9 \\
\hline
\end{tabular}

COVID-19, coronavirus disease 2019; KAP, Knowledge, Attitudes and Practices; SARS-CoV-2, severe acute respiratory coronavirus 2.

$\dagger$, Number of participants $=208$. 
regression analysis showed that having a bachelor's degree compared to having a certificate or diploma (crude odds ratio (OR): 4.68, CI: 1.07-20.44) and COVID-19 training (crude OR: 8.72, CI: 2.02-37.65) among participants were associated with COVID-19 knowledge. Therefore, participants with higher academic qualifications and COVID-19 training were 4.68 and 8.72 times more likely to have good COVID-19 knowledge (Table 4).

\section{Practice towards COVID-19 by medical laboratory personnel}

Poor practices towards COVID-19 were recorded among three-quarters of the participants. Having a master's degree or a Doctor of Philosophy compared to having a certificate or diploma (crude OR: 4.51, 95\% CI: 1.30-15.70), private or research laboratories compared to clinic or health centre laboratories (crude OR: 3.09, 95\% CI: 1.019.45) and COVID-19 training (crude OR: 12.97, 95\%

TABLE 3: Characteristics of responses for knowledge and practice towards COVID-19, Zambia, June 2020. ${ }^{\dagger}$

\begin{tabular}{|c|c|c|c|c|c|}
\hline \multirow[t]{2}{*}{ KAP aspect } & \multirow[t]{2}{*}{ Question } & \multicolumn{2}{|c|}{ Yes } & \multicolumn{2}{|c|}{ No } \\
\hline & & $n$ & $\%$ & $n$ & $\%$ \\
\hline \multirow[t]{13}{*}{ Practices towards COVID-19 } & I practise social distancing during work & 167 & 80.3 & 41 & 19.7 \\
\hline & I wear masks to help reduce transmission of COVID-19 & 199 & 95.7 & 9 & 4.3 \\
\hline & I put on PPE when processing samples & 195 & 93.8 & 13 & 6.2 \\
\hline & I process samples from the respiratory tract in a safety cabinet & 103 & 49.5 & 105 & 50.5 \\
\hline & I disinfect my work surfaces & 204 & 98.1 & 4 & 1.9 \\
\hline & We effectively dispose of all processed samples & 194 & 93.3 & 14 & 6.7 \\
\hline & We effectively dispose of disposable PPE & 181 & 87.0 & 27 & 13.0 \\
\hline & I wear masks when going out & 195 & 93.8 & 13 & 6.3 \\
\hline & I avoid crowded places & 191 & 91.8 & 17 & 8.2 \\
\hline & I have been trained in laboratory safety against COVID-19 & 71 & 34.1 & 137 & 65.9 \\
\hline & I have been involved in sampling a COVID-19 suspected patient & 52 & 25.0 & 156 & 75.0 \\
\hline & We have adequate sample referral systems & 94 & 45.2 & 114 & 54.8 \\
\hline & I have been trained in packaging of COVID-19 samples & 73 & 35.1 & 135 & 64.9 \\
\hline
\end{tabular}

COVID-19, coronavirus disease 2019; KAP, Knowledge, Attitudes and Practices; PPE, personal protective equipment.

$\dagger$, Number of participants $=208$.

TABLE 4: COVID-19 knowledge of participants and associated factors, Zambia, June 2020

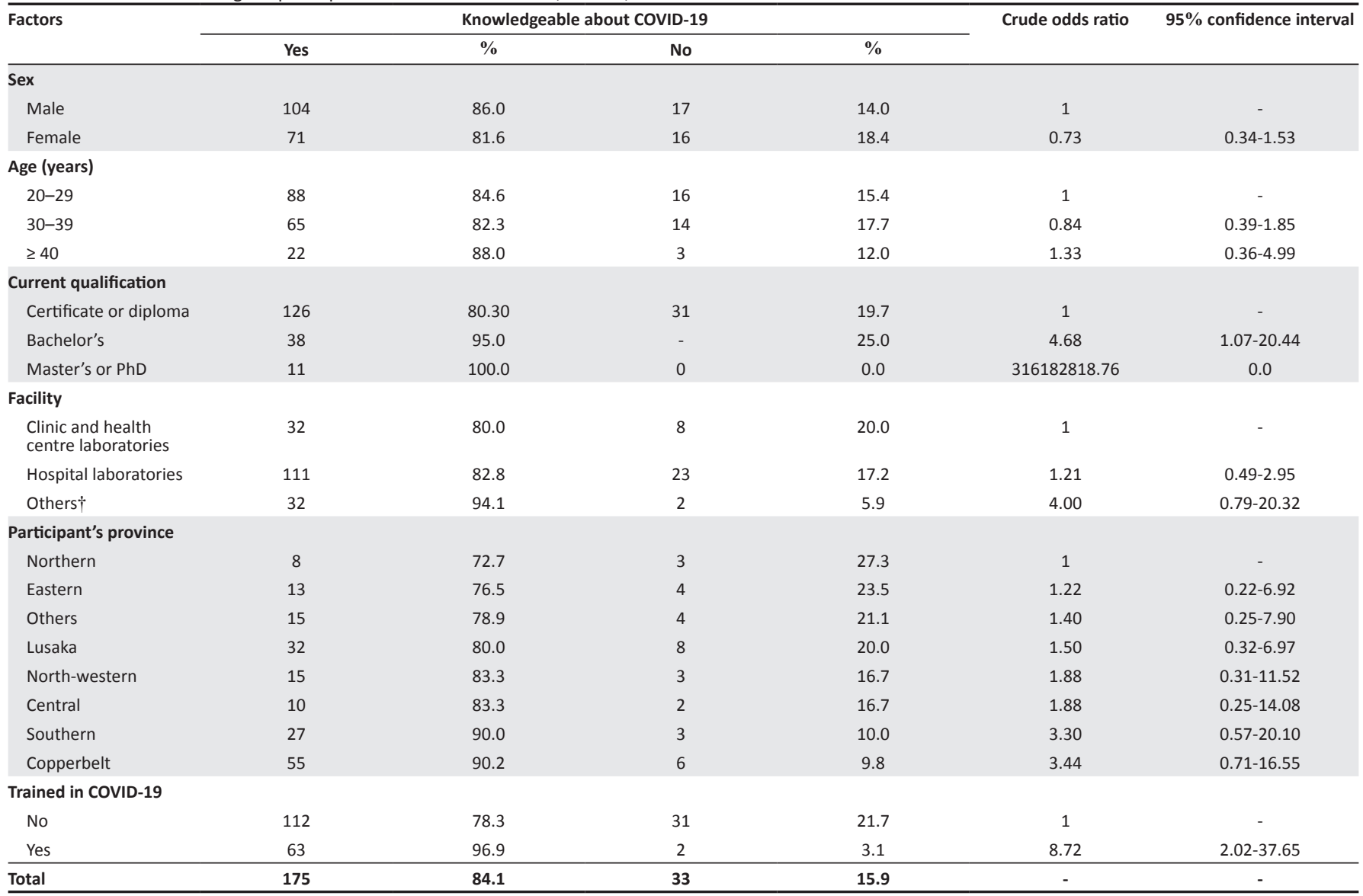

COVID-19, coronavirus disease 2019; PhD, Doctor of Philosophy.

$\dagger$, Private laboratories, research laboratories. 
TABLE 5: COVID-19 practices of participants and associated factors, Zambia, June 2020.

\begin{tabular}{|c|c|c|c|c|c|c|}
\hline \multirow[t]{2}{*}{ Factors } & \multicolumn{4}{|c|}{ Practice towards COVID-19 } & \multirow[t]{2}{*}{ Crude odds ratio } & \multirow[t]{2}{*}{$95 \%$ confidence interval } \\
\hline & Poor & $\%$ & Good & $\%$ & & \\
\hline \multicolumn{7}{|l|}{ Sex } \\
\hline Male & 92 & 76.0 & 29 & 24.0 & 1 & - \\
\hline Female & 64 & 73.6 & 23 & 26.4 & 1.14 & $0.61-2.15$ \\
\hline \multicolumn{7}{|l|}{ Age (years) } \\
\hline $20-29$ & 78 & 75.0 & 26 & 25.0 & 1 & - \\
\hline $30-39$ & 62 & 78.5 & 17 & 21.5 & 0.82 & $0.41-1.65$ \\
\hline$\geq 40$ & 16 & 64.0 & 9 & 36.0 & 1.69 & $0.67-4.28$ \\
\hline \multicolumn{7}{|l|}{ Current qualification } \\
\hline Certificate or diploma & 124 & 79.0 & 33 & 21.0 & 1 & - \\
\hline Bachelor's & 27 & 67.5 & 13 & 32.5 & 1.81 & $0.84-3.89$ \\
\hline Master's or PhD & 5 & 45.5 & 6 & 54.5 & 4.51 & $1.30-15.70$ \\
\hline \multicolumn{7}{|l|}{ Facility } \\
\hline $\begin{array}{l}\text { Clinic and health } \\
\text { centre laboratories }\end{array}$ & 34 & 85.0 & 6 & 15 & 1 & - \\
\hline Others $\dagger$ & 22 & 64.7 & 12 & 35.3 & 3.09 & $1.01-9.45$ \\
\hline \multicolumn{7}{|l|}{ Participant's province } \\
\hline Central & 11 & 91.7 & 1 & 8.3 & 1 & - \\
\hline Northern & 10 & 90.9 & 1 & 9.1 & 1.10 & $0.06-20.01$ \\
\hline North-western & 16 & 88.9 & 2 & 11.1 & 1.38 & $0.11-17.09$ \\
\hline Southern & 25 & 83.3 & 5 & 16.7 & 2.20 & $0.23-21.11$ \\
\hline Others $\ddagger$ & 15 & 78.9 & 4 & 21.1 & 2.93 & $0.29-30.01$ \\
\hline Copperbelt & 46 & 75.4 & 15 & 24.6 & 3.59 & $0.43-30.14$ \\
\hline Eastern & 10 & 58.8 & 7 & 41.2 & 7.70 & $0.80-74.05$ \\
\hline Lusaka & 23 & 57.5 & 17 & 42.5 & 8.13 & $0.96-69.17$ \\
\hline \multicolumn{7}{|l|}{ Trained in COVID-19 } \\
\hline No & 129 & 90.2 & 14 & 9.8 & 1 & - \\
\hline Yes & 27 & 41.5 & 38 & 58.5 & 12.97 & $6.19-27.18$ \\
\hline Total & 156 & 75 & 52 & 25 & - & - \\
\hline
\end{tabular}

COVID-19, coronavirus disease 2019, PhD, Doctor of Philosophy.

$\dagger$, Private laboratories, research laboratories

\$ Luapula, Muchinga and Western provinces

TABLE 6: Attitude of biomedical professionals towards coronavirus disease 2019, Zambia, June 2020.

\begin{tabular}{|c|c|c|}
\hline \multirow[t]{2}{*}{ Variables } & \multicolumn{2}{|c|}{ Response } \\
\hline & $n$ & $\%$ \\
\hline \multicolumn{3}{|c|}{$\begin{array}{l}\text { Would accept isolation from the community if } \\
\text { diagnosed with COVID-19 }\end{array}$} \\
\hline Yes & 195 & 93.8 \\
\hline No & 8 & 3.8 \\
\hline Don't know & 5 & 2.4 \\
\hline \multicolumn{3}{|c|}{$\begin{array}{l}\text { Ready to participate in anti-epidemic activities in the } \\
\text { community }\end{array}$} \\
\hline Yes & 203 & 97.6 \\
\hline No & 2 & 1.0 \\
\hline Don't know & 3 & 1.4 \\
\hline \multicolumn{3}{|c|}{$\begin{array}{l}\text { Agree that COVID-19 will finally be successfully } \\
\text { controlled }\end{array}$} \\
\hline Yes & 183 & 88.0 \\
\hline No & 10 & 4.8 \\
\hline Don't know & 15 & 7.2 \\
\hline \multicolumn{3}{|c|}{$\begin{array}{l}\text { Would accept to be vaccinated against COVID-19 if a } \\
\text { vaccine was available }\end{array}$} \\
\hline Yes & 97 & 46.6 \\
\hline No & 75 & 36.1 \\
\hline I don't know & 36 & 17.3 \\
\hline \multicolumn{3}{|c|}{$\begin{array}{l}\text { Have confidence that Zambia can win the battle } \\
\text { against the COVID-19 virus }\end{array}$} \\
\hline Yes & 162 & 77.9 \\
\hline No & 24 & 11.5 \\
\hline Don't know & 22 & 10.6 \\
\hline Total & 208 & 100.0 \\
\hline
\end{tabular}

COVID-19, coronavirus disease 2019
TABLE 7: Factors independently associated with good COVID-19 knowledge and practice, Zambia, June 2020.

\begin{tabular}{|c|c|c|}
\hline Independent factors & Adjusted odds ratio & $95 \%$ confidence interval \\
\hline \multicolumn{3}{|c|}{ Good COVID-19 knowledge } \\
\hline \multicolumn{3}{|l|}{ Current qualification } \\
\hline Certificate or diploma & 1 & - \\
\hline Bachelor's & 5 & $1.13-22.19$ \\
\hline Master's or PhD & 316182818.8 & 0 \\
\hline \multicolumn{3}{|l|}{ Trained in COVID-19 } \\
\hline No & 1 & - \\
\hline Yes & 8.83 & $2.03-38.44$ \\
\hline \multicolumn{3}{|l|}{ Good COVID-19 practices } \\
\hline \multicolumn{3}{|l|}{ Current qualification } \\
\hline Certificate or diploma & 1 & - \\
\hline Bachelor's & 2.35 & $0.93-5.95$ \\
\hline Master's or PhD & 5.23 & $1.15-23.87$ \\
\hline Trained in COVID-19 & - & - \\
\hline No & 1 & - \\
\hline Yes & 14.01 & $6.47-30.36$ \\
\hline
\end{tabular}

CI: 6.19-27.18) were associated with good COVID-19 practices (Table 5).

\section{Attitude towards COVID-19 among medical laboratory personnel}

About $93.8 \%$ of participants reported that they would accept isolation from the community if diagnosed with COVID-19. 
A few (46.6\%) would accept to be vaccinated against COVID-19 if a vaccine was available. On the other hand, many participants $(97.6 \%)$ were ready to take part in antiepidemic community activities. Our study revealed that $77.9 \%$ were confident that Zambia could win the battle against the COVID-19 virus (Table 6).

\section{Factors independently associated with good knowledge and practice about COVID-19}

After controlling for possible confounding factors, having a higher current qualification (bachelor's degree) and COVID-19 training were independently associated with good COVID-19 knowledge among biomedical professionals in Zambia. Similarly, having a higher current qualification (master's degree or a Doctor of Philosophy) and COVID-19 training were independently associated with good COVID-19 practice (Table 7).

\section{Discussion}

Very few studies worldwide have documented knowledge, attitudes and practices among HCWs towards COVID-19 due to the novel nature of the disease..$^{22}$ Our study findings showed that the majority of medical laboratory professionals in Zambia had good knowledge of COVID-19. The level of knowledge on COVID-19 among participants was similar irrespective of their gender, age and laboratory facility. These findings are encouraging as they indicate that there are no inherent differences in knowledge of COVID-19 among groups based on unique demographic characteristics in the population. The majority of participants exhibited poor practices towards COVID-19 contrary to findings from Uganda and Nepal. ${ }^{19,22}$ Differences in knowledge and practice regarding COVID-19 have been reported before in a study by Asemahagn. ${ }^{24}$ Most participants with poor practices were those who had certificate qualifications, those without prior COVID-19 training and those from clinic and health centre laboratories. This could be attributed to limited resources, health information and laboratory materials in most clinic and health centre laboratories found in rural areas. Poor practices can lead to delayed or wrong laboratory diagnosis, leading to poor patient management or safety incidents that could harm the personnel and their immediate co-workers, families and patients or laboratory clients. ${ }^{25}$

Current qualification and COVID-19 training among participants were significantly associated with good COVID-19 knowledge, a finding similar to that obtained by a study in Vietnam, ${ }^{26}$ but contrary to the findings of Bhagavathula and others. ${ }^{27}$ Our findings show that participants with higher academic qualifications and COVID-19 training were 4.68 and 8.72 times more likely to have good COVID-19 knowledge. The current qualification was also significantly associated with good COVID-19 practices which agrees with study findings from Uganda. ${ }^{22}$ On the other hand, the type of laboratory facility and COVID-19 training were significantly associated with good COVID-19 practices. This shows that participants who received COVID-19 training were 12.97 times more likely to have good practices towards COVID-19 and general infection prevention; this is in agreement with similar studies in Nepal and Ethiopia. ${ }^{19,28}$

\section{Limitations}

The study may be susceptible to self-presentation bias as it was based on an online questionnaire. The study was limited by the level of responses available and could have been strengthened by increasing the range of answers using, for example, a five-point Likert scale. The questions on attitude were limited and therefore not powerful enough to generate meaningful conclusions on the attitude of respondents. The study could not capture dropouts and respondents who refused consent as only individuals who consented and submitted the questionnaire had their responses recorded.

\section{Conclusion}

Our study found that medical laboratory professionals in Zambia have good knowledge regarding COVID-19. The current qualification and COVID-19 training were independently associated with COVID-19 knowledge and practice. As cases of COVID-19 continue to be recorded in the country, there is need for continuous professional development among medical laboratory personnel as a key intervention in improving their contribution to COVID-19 control efforts.

\section{Acknowledgements}

The authors are grateful to the Biomedical Society of Zambia and its members for facilitating the distribution of questionnaires to the medical laboratory personnel.

\section{Competing interests}

The authors declare that they have no financial or personal relationships that may have influenced the writing of this article.

\section{Authors' contributions}

A.C., R.L.M., G.M. and V.D. conceptualised the study. A.C., S.D.Z., P.A.V., S.M., K.M., M.C.-K., J.M. and T.M. developed the data collection tools. A.C., P.M.S., M.C. and V.D. performed the formal analysis and interpretation. A.C., R.L.M., P.A.V., K.M. and V.D. wrote the first draft manuscript. All authors read and approved the final manuscript.

\section{Sources of support}

This research was not supported by any external funding.

\section{Data availability statement}

The data analysed in this study can be made available on request from the corresponding author. 


\section{Disclaimer}

The views and opinions expressed in this article are solely of the authors and do not reflect the official policy or position of any affiliated organisation of the authors.

\section{References}

1. Modi PD, Nair G, Uppe A, et al. COVID-19 awareness among healthcare students and professionals in Mumbai metropolitan region: A questionnaire-based survey. Cureus. 2020;124. https://doi.org/10.7759/cureus.7514

2. Madjid M, Safavi-Naeini P, Solomon SD, Vardeny O. Potential effects of coronaviruses on the cardiovascular system: A review JAMA Cardiol. coronaviruses on the cardiovascular system: A review
2020;5:831-840. https://doi/org10.1001/jamacardio.2020.1286

3. Zhong BL, Luo W, Li HM, et al. Knowledge, attitudes, and practices towards COVID-19 among Chinese residents during the rapid rise period of the COVID-19 outbreak: A quick online cross-sectional survey. Int J Biol Sci. 2020;16(10):1745-1752. https://doi.org/10.7150/ijbs.45221

4. Jean SS, Lee PI, Hsueh PR. Treatment options for COVID-19: The reality and challenges. J Microbiol Immunol Infect [serial online]. 2020 [cited 2020 Sep 13];53(3):436-443. https://doi.org/10.1016/j.jmii.2020.03.034

5. Li L, Li R, Wu Z, et al. Therapeutic strategies for critically ill patients with COVID-19. Ann Intensive Care [serial online]. 2020;10:45. https://doi.org/10.1186/s13613020-00661-z

6. Wu R, Wang $L$, Kuo $H C D$, et al. An update on current therapeutic drugs treating COVID-19. Curr Pharmacol Rep. 2020;6:56-70. https://doi.org/10.1007/s40495020-00216-7

7. Peng $Y$, Pei $C$, Zheng $Y$, et al. Knowledge, attitude and practice associated with COVID-19 among university students: A cross-sectional survey in China. BMC Public Health. 2020, 1292. https://doi.org/10.21203/rs.3.rs-21185/v1

8. Güner R, Hasanoğlu i, Aktaş F. COVID-19: Prevention and control measures in community. Turkish J Med Sci. 2020;50:571-577. https://doi.org/10.3906/sag2004-146

9. Cucinotta D, Vanelli M. WHO declares COVID-19 a pandemic. Acta Biomedica. 2020;91:157-160. https://doi.org/10.23750/abm.v91i1.9397

10. WHO. Coronavirus disease (COVID-19) situation reports [homepage on the Internet]. 2020 [cited 2020 Sep 17]. Available from: https://www.who.int/ emergencies/diseases/novel-coronavirus-2019/situation-reports/

11. $\mathrm{MOH}$. Zambia COVID-19 general dasboard [homepage on the Internet]. 2020 cited 2020 Sep 17]. Available from: https://rtc-planning.maps.arcgis.com/apps/ opsdashboard/index.html\#/3b3a01c1d8444932ba075fb44b119b63

12. Chileshe M, Mulenga D, Mfune RL, et al. Increased number of brought-in-dead case with COVID-19: Is it due to poor health-seeking behaviour among the Zambian population? Pan Afr Med J [serial online]. 2020 [cited 2020 Oct 14];37. Available from: https://www.panafrican-med-journal.com/content/article/37/136/fulls

13. WHO. Situation report-82 highlights [homepage on the Internet]. Geneva; 2020 [cited $2020 \mathrm{Sep} \mathrm{13]}$. Available from: http://weekly.chinacdc.cn/en/article/id/ e53946e2-c6c4-41e9-9a9b-fea8db1a8f51

14. Wang $\mathrm{H}$, Liu $\mathrm{Y}, \mathrm{Hu} \mathrm{K}$, et al. Healthcare workers' stress when caring for COVID-19 patients: An altruistic perspective. Nurs Ethics [serial online] 2020;27(7):1490-1500. https://doi.org/10.1177/0969733020934146
15. Burrer SL, De Perio MA, Hughes MM, et al. Characteristics of health care personne with COVID-19 - United States, February 12-April 9, 2020. MMWR Morb Mortal Wkly Rep [serial online]. 2020 [cited 2020 Sep 13];69(15):477-481. Available from: http://www.cdc.gov/mmwr/volumes/69/wr/mm6915e6.htm?s_cid=mm6915e6_w

16. WHO. Over 10000 health workers in Africa infected with COVID-19 [homepage on the Internet]. WHO, Regional Office for Africa. 2020 [cited 2020 Sep 17]. Available from: https://www.afro.who.int/news/over-10-000-health-workers-africa-infectedcovid-19

17. Tait FN, Mburu C, Gikunju J. Occupational safety and health status of medical laboratories in Kajiado county, Kenya. Pan Afr Med J [serial online]. 2018;29:65. https://doi.org/10.11604/pamj.2018.29.65.12578

18. Pourhoseingholi MA, Vahedi M, Rahimzadeh M. Sample size calculation in medical studies. Gastroenterol Hepatol Bed Bench [serial online]. 2013 [cited 2020 Oct 23];6(1):14-17. Available from: https://pubmed.ncbi.nlm.nih.gov/24834239/

19. Nepal R, Sapkota K, Adhikari K, et al. Knowledge, attitude and practice regarding COVID-19 among healthcare workers in Chitwan, Nepal. 2020 [cited 2020 Sep 14];In press. https://doi.org/10.21203/rs.3.rs-26774/v1

20. Azlan AA, Hamzah MR, Sern TJ, Ayub SH, Mohamad E. Public knowledge, attitudes and practices towards COVID-19: A cross-sectional study in Malaysia. PLoS One. 2020;15(5):e0233668. https://doi.org/10.1371/journal.pone.0233668

21. Taber KS. The use of Cronbach's alpha when developing and reporting research instruments in science education. Res Sci Educ. 2018;48(6):1273-1296. https:// doi.org/10.1007/s11165-016-9602-2

22. Olum R, Chekwech G, Wekha G, Nassozi DR, Bongomin F. Coronavirus disease-2019: Knowledge, attitude, and practices of health care workers at Makerere University teaching hospitals, Uganda. Front Public Heal. 2020;8:181 https://doi.org/10.3389/fpubh.2020.00181

23. Akalu Y, Ayelign B, Molla MD. Knowledge, attitude and practice towards COVID-19 among chronic disease patients at Addis Zemen Hospital, Northwest Ethiopia. Infect Drug Resist [serial online]. 2020 [cited 2020 Oct 26];13:1949-1960. Available from: https://www.dovepress.com/knowledge-attitude-and-practicetowards-covid-19-among-chronic-disease-peer-reviewed-article-IDR

24. Asemahagn MA. Factors determining the knowledge and prevention practice of healthcare workers towards COVID-19 in Amhara region, Ethiopia: A crosssectional survey. Trop Med Health. 2020;48:72. https://doi.org/10.1186/s41182 020-00254-3

25. Nakhleh RE, Nosé V, Colasacco C, et al. Interpretive diagnostic error reduction in surgical pathology and cytology: Guideline from the college of American Pathologists pathology and laboratory quality center and the association of directors of anatomic and surgical pathology. Arch Pathol Lab Med. 2016;140(1):29-40.

26. Giao H, Le An P, Thi Ngoc Han N, Van Khanh T, Kim Ngan V, Van Tam V. Knowledge and attitude toward COVID-19 among healthcare workers at District 2 Hospital, Ho Chi Minh City. Asian Pac J Trop Med. 2020;13(6):6-11. https://coi. org/10.4103/1995-7645.280396

27. Bhagavathula AS, Aldhaleei WA, Rahmani J, Mahabadi MA, Bandari DK. Knowledge and perceptions of COVID-19 among health care workers: Cross-sectional study. JMIR Public Heal Surveill. 2020;6(2):e19160.

28. Geberemariyam BS, Donka GM, Wordofa B. Assessment of knowledge and practices of healthcare workers towards infection prevention and associated factors in healthcare facilities of West Arsi District, Southeast Ethiopia: A facilityfactors in healthcare facilities of West Arsi District, Southeast Ethiopia: A facility-
based cross-sectional study. Arch Public Heal. 2018;76(69). https://doi. based cross-sectional study. Arch
org/10.1186/s13690-018-0314-0 